\title{
Sociedade, cultura e saúde: motivação na utilização de espaço público de lazer
}

\author{
Emília Amélia Pinto Costa da Silva* \\ Leonardo dos Santos Oliveira** \\ Priscilla Pinto Costa da Silva*** \\ Bruno Medeiros Roldão de Araújo**** \\ Iraquitan de Oliveira Caminha****** \\ Clara Maria Silvestre Monteiro de Freitas ${ }^{* * * * * *}$
}

Resumo: O objetivo dessa pesquisa foi identificar e analisar os fatores motivacionais que influenciam os atores sociais a utilizarem os espaços públicos de lazer. Trata-se de uma pesquisa descritiva de campo, com abordagem qualitativa, realizada com 80 frequentadores do Parque da Jaqueira e Calçadão de Boa Viagem, da cidade de Recife-PE. A apreciação dos dados se deu através da análise de conteúdo. Os resultados indicam os fatores motivacionais para se frequentar os espaços públicos de lazer estão relacionados à busca por hábitos saudáveis e à interação social. Portanto, podem proporcionar, aos seus usuários qualidade de vida, satisfação e bem estar.

Palavras- chave: Atividades de lazer. Promoção da saúde. Motivação.

‘Professora mestre da Faculdade Maurício de Nassau. E-mail: milapcosta@hotmail.com

"Professor mestre da Faculdade Maurício de Nassau. E-mail: leosoliveira@uol.com.br

"."Professora mestre da Faculdade Maurício de Nassau. E-mail: Iaprisci@gmail.com

"..*Professor mestre da Universidade Federal de Campina Grande. E-mail: bruno.mr.araujo@ufcg.edu.br

...."Professor doutor da Universidade Federal da Paraíba. E-mail: iraqui@uol.com.br

......Professora pós- doutora da Universidade de Pernambuco. E-mail: clarasilvestre@uol.com.br 


\section{INTRODUÇÃO}

Os parques e praças são importantes espaços públicos que possibilitam convívio social (RECHIA, 2005; FERREIRA, 2007; RECHIA; BELTRÁN, 2010), prática de atividade física (BEDIMORUNG; MOWEN; COHEN, 2005; COLLET et al., 2008; FLORINDO et al. 2011), melhorar a relação homem-natureza (RECHIA, 2003; SCHWARTZ, 2006), diferentes oportunidades de lazer (OLIVEIRA; RECHIA, 2009), entre outros. Além disso, a qualidade destes espaços pode influenciar os fatores motivacionais de seus frequentadores. Neste sentido, o ambiente de lazer pode ser um local propiciador de qualidade de vida, socialização e saúde.

Tanto os parques quanto praças públicas são utilizados de forma distinta por seus frequentadores, possibilitando, dessa maneira, as mais variadas representações que cada sujeito faz desses lugares como espaço de lazer (STIGGER; MELATI; MANZO, 2010). Esses ambientes podem ser significativos para seus usuários, devido os benefícios que proporcionam. No entanto, necessitam ser amparados por uma infra-estrutura organizada, que possibilite um interesse de utilização pelos usuários (ZIPEROVICH, 2007).

Assim, tais espaços precisam estar de acordo com os interesses dos usuários. A esse respeito, Leite (2011) comenta que as principais características de um espaço público são aquelas que têm relações com a vida pública. Portanto a utilização desses ambientes está, diretamente, relacionada com a sua adequação funcional no que diz respeito à morfologia e à utilização do espaço e/ou equipamento; adequação estética que insere o visual do lugar; e, por fim, as características ambientais que estão atreladas aos aspectos naturais apreciados nos espaços.

Nesta perspectiva, os parques urbanos e de preservação estão sendo valorizados por possibilitar diferentes formas de lazer, como também a relação homem-natureza (COLLET et al., 2008). Além disso, esses ambientes podem ser um mecanismo de atração para que os indivíduos tornem-se, fisicamente ativos, uma vez que o acesso 
aos recursos disponíveis nos espaços públicos pode contribuir para promoção da saúde e atividade física (BEDIMO-RUNG; MOWEN; COHEN, 2005; BAKER et al., 2008).

Além dos benefícios de ordem anátomo-fisiológicos, os espaços de lazer podem também estimular as relações sociais. Para Leite (2011, p.159), "praças, ruas, jardins e parques, em suas múltiplas funções, constituem o cerne do sistema de espaços livres das cidades, e neles a sociabilidade não pode ser relegada a plano secundário". Logo, os espaços públicos de lazer são lugares de interação humana e mediação social. A partir dessas considerações, esse estudo objetiva identificar e analisar os fatores motivacionais que influenciam os sujeitos a utilizarem os espaços públicos de lazer, considerando os aspectos social, cultural e da saúde.

\section{Metodologia}

Trata-se de uma pesquisa descritiva de campo, com abordagem qualitativa, pelo fato de aproximar o pesquisador às experiências com o cenário estudado, sendo realizada em condições naturais em que o fenômeno ocorre, sem a necessidade de intervenções do pesquisador (BANKS, 2009).

Foram delimitados, de forma intencional, dois espaços de lazer na cidade do Recife-PE, sendo eles o Parque da Jaqueira e o Calçadão de Boa Viagem, pelo fato de serem ambientes de livre acesso e de grande circulação de pessoas, além de possibilitarem diferentes atrativos no que diz respeito à vivência de lazer e à prática de atividade física. Ambos os espaços oferecem pista de caminhada, ciclovia, playground e projetos de cunho socioeducativos desenvolvidos pela Prefeitura da Cidade do Recife, como por exemplo, a Academia da Cidade.

A amostragem se caracteriza como acidental por saturação, pois, conforme Fontanella, Ricas e Turato (2008), é uma ferramenta usada, frequentemente, nas pesquisas qualitativas, recomendada para estabelecer ou fechar o tamanho da amostra. Neste sentido, o ponto 
de saturação deu-se a partir do momento em que as respostas das entrevistas começaram a se tornar repetitivas, não adicionando informações e revelando dados suficientes para atender o objetivo do presente estudo. Assim, a amostra foi constituída por 80 atores sociais, com 40 sujeitos de cada espaço delimitado.

Foram incluídos usuários do Parque da Jaqueira e/ou Calçadão de Boa Viagem, moradores da cidade do Recife, de ambos os sexos, com idade superior a 18 anos, sem restrição de escolaridade ou área profissional que aceitaram participar da pesquisa. Foram excluídos usuários que não residiam na cidade do Recife nos últimos seis meses, turistas ou sujeitos que não completaram a entrevista.

Como instrumento, empregou-se um roteiro de entrevista semiestruturada, elaborado pelos autores, de modo a contemplar questões sobre o interesse do uso dos espaços públicos de lazer, as principais atividades desenvolvidas nesses lugares e o significado desses ambientes na vida dos seus frequentadores. Tal instrumento permite o pesquisador inserir outras perguntas para esclarecer e aprofundar questões relevantes (BANKS, 2009). A entrevista contemplou aspectos no tocante à relação dos usuários com os espaços delimitados. A coleta de dados se deu entre os meses de março a maio de 2011. Cada entrevista durou, aproximadamente, 20 minutos, sendo realizada nos próprios espaços delimitados, no período da manhã e da tarde, em diferentes dias da semana.

$\mathrm{Na}$ apreciação das informações coletadas, a estratégia seguida foi a análise de conteúdo de Bardin (2009), do tipo temático. Para obtenção da frequência absoluta dos termos, utilizou-se o Analysis of Qualitative Data - AQUAD 6 e, para apresentação dos diagramas, o software GoDiagram Express versão 2.6.2.

Os dados de variáveis categóricas foram reportados por frequência absoluta e relativa, com análise de respostas múltiplas, quando necessária. Estes valores foram calculados com o auxílio do programa SPSS v.10.

Este estudo foi aprovado pelo Comitê de Ética em Pesquisa com seres humanos da Universidade de Pernambuco, com o registro 
022/11, conforme a resolução $n^{\circ}$ 196/96 do Conselho Nacional de Saúde (BRASIL, 2003). Ressalta-se que a prefeitura da cidade de Recife permitiu a realização das entrevistas nos espaços públicos de lazer, por meio da Carta de Anuência. Os participantes do estudo foram esclarecidos quanto aos objetivos, procedimentos, privacidade das informações e assinaram um Termo de Consentimento Livre e Esclarecido.

\section{Resultados}

A análise e interpretação dos dados, advindos das entrevistas, possibilitaram a classificação dos resultados em três etapas. Primeiramente, será apresentado o perfil sociodemográfico dos sujeitos participantes da pesquisa. Em seguida, as atividades realizadas pelos atores sociais nos espaços delimitados para o estudo e, por fim, será discutida a categoria Motivos para Frequentar os Espaços de Lazer.

No que se refere ao perfil sociodemográfico, a média de idade dos frequentadores de ambos os espaços foi de 40,85 anos. No Parque da Jaqueira, constatou-se a menor idade 22 anos e a maior idade 78 anos e, no Calçadão, a menor idade foi 19 anos e a maior 66 anos. Percebeu-se a prevalência do sexo feminino no Parque da Jaqueira $(55,0 \%)$ e no Calçadão de Boa Viagem, o sexo masculino (77,5\%). Em relação ao grau de escolaridade, 37,5\% dos usuários da Jaqueira concluíram o Ensino Médio e 30\% o Ensino Superior, já no que diz respeito aos usuários do Calçadão, 60,0\% possuíam o Ensino Médio completo e 15,0\% o Ensino Superior. No Parque da Jaqueira, 35,0\% dos indivíduos frequentavam até duas vezes por semana e $25,0 \%$ dos entrevistados do Calçadão de Boa Viagem até quatro vezes por semana (Tabela 1). 
Tabela 1 - Caracterização sociodemográfica e aspectos relacionados à utilização dos espaços públicos de lazer da cidade de Recife-PE ( $\mathrm{n}=80)$

\begin{tabular}{|c|c|c|c|c|}
\hline Variável & $\mathbf{n}$ & $\%$ & $\mathbf{n}$ & $\%$ \\
\hline & \multicolumn{2}{|c|}{ Parque da Jaqueira } & \multicolumn{2}{|c|}{$\begin{array}{c}\text { Calçadão de Boa } \\
\text { Viagem }\end{array}$} \\
\hline \multicolumn{5}{|l|}{ Sexo } \\
\hline Homem & 18 & 45,0 & 31 & 77,5 \\
\hline Mulher & 22 & 55,0 & 9 & 22,5 \\
\hline \multicolumn{5}{|l|}{ Faixa etária } \\
\hline 19 a 34 anos & 15 & 37,0 & 18 & 45,0 \\
\hline 35 a 49 anos & 10 & 25,0 & 14 & 35,0 \\
\hline 50 a 59 anos & 7 & 17,5 & 4 & 10,0 \\
\hline 60 a 78 anos & 8 & 20,0 & 4 & 10,0 \\
\hline \multicolumn{5}{|l|}{ Escolaridade } \\
\hline Analfabeto & - & - & 1 & 2,5 \\
\hline Ensino fundamental I incompleto & 2 & 5,0 & 1 & 2,5 \\
\hline Ensino fundamental I completo & 3 & 7,5 & 1 & 2,5 \\
\hline Ensino fundamental II incompleto & 4 & 10,0 & 3 & 7,5 \\
\hline Ensino fundamental II completo & 2 & 5,0 & 2 & 5,0 \\
\hline Ensino médio incomple to & - & - & 2 & 5,0 \\
\hline Ensino médio completo & 15 & 37,5 & 24 & 60,0 \\
\hline Superior incompleto & 2 & 5,0 & - & - \\
\hline Superior completo & 12 & 30,0 & 6 & 15,0 \\
\hline \multicolumn{5}{|l|}{ Frequência nos espaços de lazer } \\
\hline Todos os dias & 1 & 2,5 & 6 & 15,0 \\
\hline Até $2 \mathrm{x} /$ semana & 14 & 35,0 & 8 & 20,0 \\
\hline Até $4 x /$ semana & 11 & 27,5 & 10 & 25,0 \\
\hline Até $6 x /$ semana & 2 & 5,0 & 5 & 12,5 \\
\hline Apenas dias de semana & 11 & 27,5 & 8 & 20,0 \\
\hline Apenas no final de semana & 1 & 2,5 & 3 & 7,5 \\
\hline
\end{tabular}

Fonte: Silva (2011)

A partir da análise de respostas múltiplas, os sujeitos do Parque da Jaqueira definiram o ficar sentado $(90,0 \%)$ e a caminhada $(87,5 \%)$ como as principais atividades realizadas. Em relação ao Calçadão, os sujeitos afirmaram que vão ali para encontrar amigos $(92,5 \%)$ e ficar sentado $(90,0 \%)$. Esses resultados podem ser visualizados na Tabela 2, a seguir. Por outro lado, com um percentual, ligeiramente, menor, verificou-se que encontrar amigos $(80,0 \%)$ e realizar alongamento $(72,5 \%)$ também foram atividades representativas para os entrevistados da Jaqueira e, a caminhada (77,5\%) e realizar alongamento (77,5\%) para os indivíduos do Calçadão (Tabela 2). 
Considerando os resultados de ambos os espaços, constatou-se que as atividades mais desenvolvidas foram a caminhada $(90,0 \%)$ e o ficar sentado $(87,5 \%)$. Em relação a participação de projetos de esporte e lazer, percebeu-se que apenas $15 \%$ dos usuários da Jaqueira e $15,5 \%$ do Calçadão de Boa Viagem afirmaram participar.

Tabela 2 - Atividades físicas/lazer realizadas nos espaços públicos de lazer da cidade de Recife-PE

\begin{tabular}{lcccccc}
\hline \multicolumn{1}{c}{ Variável } & $\mathbf{n}$ & $\mathbf{\%}$ & $\begin{array}{c}\mathbf{\%} \\
\text { casos }\end{array}$ & $\mathbf{n}$ & $\mathbf{\%}$ & $\begin{array}{c}\mathbf{\%} \\
\text { casos }\end{array}$ \\
\hline Alongamento & \multicolumn{3}{c}{ Parque da Jaqueira } & \multicolumn{2}{c}{ Calçadão de Boa Viagem } \\
Jogar bola & 29 & $12,9 \%$ & $72,5 \%$ & 31 & $13,0 \%$ & $77,5 \%$ \\
Acompanhar crianças & 9 & $4,0 \%$ & $22,5 \%$ & 18 & $7,6 \%$ & $45,0 \%$ \\
Caminhada & 25 & $11,2 \%$ & $62,5 \%$ & 16 & $6,7 \%$ & $40,0 \%$ \\
Corrida & 35 & $15,6 \%$ & $87,5 \%$ & 35 & $14,7 \%$ & $87,5 \%$ \\
Ficar sentado & 25 & $11,2 \%$ & $62,5 \%$ & 29 & $12,2 \%$ & $72,5 \%$ \\
Andar de bicicleta & 36 & $16,1 \%$ & $90,0 \%$ & 36 & $15,1 \%$ & $90,0 \%$ \\
Participação em projetos & 13 & $5,8 \%$ & $32,5 \%$ & 18 & $7,6 \%$ & $45,0 \%$ \\
Encontrar amigos & 32 & $14,3 \%$ & $80,0 \%$ & 37 & $15,5 \%$ & $92,5 \%$ \\
Outros & 6 & $2,7 \%$ & $15,0 \%$ & 7 & $2,9 \%$ & $17,5 \%$ \\
Total & 14 & $6,2 \%$ & $35,0 \%$ & 11 & $4,6 \%$ & $27,5 \%$ \\
\hline A & 224 & $100,0 \%$ & $560,0 \%$ & 238 & $100,0 \%$ & $595,0 \%$ \\
\hline
\end{tabular}

A coluna percentual (\%) representa a frequência total de respostas por atividade e a coluna percentual de casos (\% casos) indica a frequência de casos válidos para cada atividade.

Fonte: Silva (2011)

A técnica de análise de conteúdo possibilitou o cruzamento das respostas, gerando a categoria Motivos para Frequentar os Espaços de Lazer (Figura 1), representada na cor cinza escuro, a qual se refere aos motivos que levam os usuários a utilizarem o Parque da Jaqueira e o Calçadão de Boa Viagem. As subcategorias, em destaque, na cor cinza claro, revelam as características dos locais estudados, sendo elas: Comodidade, que está relacionada com as facilidades em frequentar os espaços de lazer; Contato com a natureza, que se refere os elementos naturais encontrados nos ambientes de lazer; Espaço de lazer e promoção da saúde, que apontaram as características físicas oferecidas no espaço que podem promover hábitos saudáveis aos usuários; e, Atividade física, remetendo as práticas oferecidas nos ambientes estudados. Na cor 
branca, estão apresentadas as variáveis de maior frequência, referente a cada espaço estudado. Deste modo, foi constatado, que esses motivos estão relacionados à localidade, às características do espaço e à promoção da saúde.

Figura 1 - Motivos para frequentar os espaços públicos de Lazer de

Recife-PE (2011)

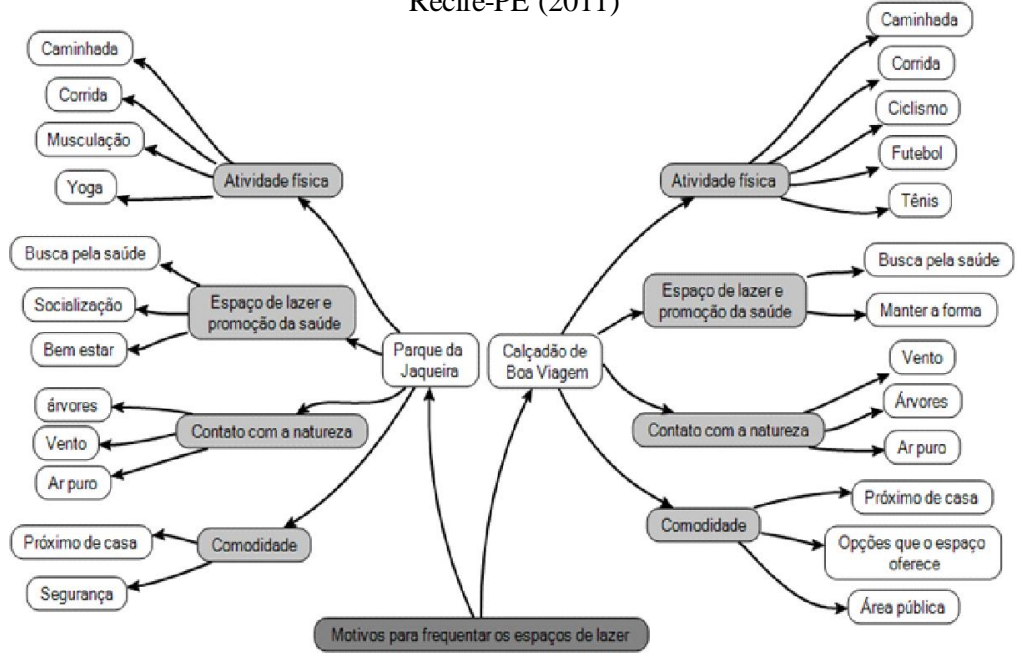

Fonte: Silva (2011)

\section{Discussão}

Ao analisar os resultados obtidos no presente estudo, percebeuse, no Parque da Jaqueira, a maior participação de mulheres, sendo importante salientar que este espaço é fechado, podendo dar maior segurança às usuárias. No que se refere ao Calçadão de Boa Viagem, a maioria dos entrevistados era do sexo masculino. Estudos de natureza similar (COHEN et al., 2007; SANTOS, 2007; COLLET et al., 2008; CASSOU, 2009; SILVA; PETROSKI; REIS, 2009; ROTTA; PIRES, 2010), também encontraram maior evidência da presença do sexo masculino nos espaços públicos de lazer. 
Na variável idade, constatou-se que a maioria dos entrevistados da Jaqueira e do Calçadão de Boa Viagem é adulto. Esse resultado também foi percebido no estudo de Cohen et al.(2007), em que 43\% dos usuários observados eram adultos. Esses achados também são semelhantes ao estudo de Santos (2007), em que as faixas etárias $15-24$ anos $(30,3 \%)$ e 25-34 anos (26,4\%) foram as mais encontradas no que diz respeito à utilização de parques públicos de lazer. A frequência em utilizar os espaços delimitados pode estar diretamente ligada às opções que o local oferece e, neste sentido, a predominância recaiu em frequentar até duas vezes (Jaqueira) ou até quatro vezes (Boa Viagem) por semana.

Nos dois espaços, as atividades mais citadas pelos entrevistados foram ficar sentado, caminhada, encontrar amigos e realizar alongamento. Destacam-se o interesse/motivação dos usuários utilizarem o espaço de lazer para praticar atividades físicas. Esse fenômeno foi observado por Cassou (2009), em que as atividades mais prevalentes foram caminhadas, corridas e alongamentos e, no estudo de Meunier (2009), destacam-se as caminhadas com maior frequência.

Em relação à participação de projetos de esporte e lazer, constatou-se que, parte significativa da amostra, tanto da Jaqueira quanto do Calçadão, não participa. A esse respeito, quando questionado sobre os programas de esporte e lazer, o Entrevistado 34 do Parque da Jaqueira alegou que "eu não conheço quase nenhum aqui dentro". Por sua vez, o Entrevistado 72 do Calçadão, contestou os horários oferecidos pelos programas, relatando que "não tem uma frequência. Tem um horário muito irregular, que não tem uma combinação com o tempo das pessoas. Porque, ou fazem muito cedo, ou fazem muito tarde, quer dizer, fica uma coisa muito descombinada com o lazer da pessoa". Neste caso, tornam-se necessárias estratégias de divulgação dos projetos realizados nesses espaços.

Em contrapartida, os atores sociais que conhecem e participam dos referidos projetos mostram-se entusiasmados com essa prática, como é o caso do Entrevistado 49 do Calçadão de Boa Viagem que afirmou frequentar o espaço delimitado para o estudo "porque tem 
aqui o pólo da Academia. Que a gente frequenta e faz os exercícios todos os dias, são variados, são muito bons, por sinal, e a gente tem todo o retorno". Nesta perspectiva, a Academia da Cidade é um dos projetos mais citados pelos entrevistados, sendo este um programa oferecido pela Prefeitura de Recife que oportuniza a prática de atividade física, em que são oferecidos aulas gratuitamente para a população. De acordo com a Organização Mundial de Saúde - OMS (1998), as iniciativas de promoção da saúde por meio de programas e atividades físicas, devem ser caracterizadas a partir dos sete princípios definidos pela OMS, sendo um deles a concepção holística que determina iniciativas de promoção a saúde física, mental e espiritual. Assim, é importante a ampliação de programas voltados ao esporte e ao lazer que proporcione um melhor aproveitamento no que diz respeito a qualidade de vida e promoção da saúde para a população.

Concernente às relações sociais, a predominância recaiu no encontrar amigos e acompanhar crianças. Constatou-se que os usuários do Parque da Jaqueira acompanham mais as crianças, quando comparado com o Calçadão de Boa Viagem, visto que a Jaqueira dispõe de mais equipamentos direcionados às crianças, além de ser mais arborizado. De fato, observa-se que os espaços públicos de lazer desempenham e potencializam uma função de relações sociais, oferecendo um espaço capaz de propiciar encontros e laços sociais. A esse respeito, o estudo de Rechia (2003) apontou que os parques possibilitam a sociabilidade, oportunizando novas formas de relações dos sujeitos consigo mesmos e com o outro. Conforme Ryan e Deci (2000), os seres humanos estão motivados pela interação social e a motivação pode estar relacionada ao interesse de utilizar os espaços para prática de lazer, objetivando o bem estar.

No que tange à categoria Motivos para frequentar os espaços de lazer, os sujeitos apresentaram, em suas falas, elementos relacionados ao aspecto estrutural dos lugares. Uma das razões de frequentar os espaços de lazer está relacionada com a subcategoria Comodidade. Dentre os fatores motivacionais, considerou-se a proximidade das residências dos entrevistados em ambos os espaços. 
Um estudo de Reis (2001), realizado no Jardim Botânico da cidade de Curitiba, identificou que a proximidade dos parques com as residências dos usuários é um importante fator para utilização desse ambiente. No estudo de Cohen et al. (2007), os usuários, que moravam perto do parque, informaram que o utilizam cinco ou mais vezes por semana.

$\mathrm{Na}$ Jaqueira, outro fator motivante foi a segurança, esses resultados ressaltam a importância da segurança nos espaços públicos, podendo ser um fator determinante para os usuários. Em um estudo recente, Silva, Petroski e Reis (2009), 55\% dos participantes alegaram que a segurança pública foi considerada um fator determinante para a prática de atividade física. Já em relação ao Calçadão, as opções que o ambiente oferece tais como espaços apropriados para atividade física e contato social, além de ser uma área pública, são consideradas fatores que motivam os usuários. No que se refere à área pública, o Entrevistado 58 do Calçadão assinalou que os motivos que o levam a frequentar o espaço de lazer é "porque aqui é área pública e, pode todo mundo participar". De fato, o espaço público é o espaço da sociedade (NARCISO, 2009), sendo importante a conscientização do uso dessas áreas, principalmente no que diz respeito aos espaços de lazer, pois são ambientes propícios a promoção da saúde e socialização, por terem estruturas que possibilitam práticas saudáveis.

No que tange à subcategoria Contato com a Natureza, os entrevistados de ambos os espaços, apontaram que os elementos naturais, como árvores, vento e ar puro são características ambientais que motivam os sujeitos a frequentarem os espaços de lazer. Assim, quando questionados sobre quais os motivos que os levam a frequentar os espaços de lazer, o Entrevistado 29 da Jaqueira ressaltou "o ambiente e o verde" e o Entrevistado 60 do Calçadão afirmou que o "respirar esse ar bom que tem aqui. Um ar puro, diferente, a brisa do mar é muito boa. Então você se sente bem melhor depois que você faz isso algumas vezes na semana". Resultados similares foram encontrados por Oliveira (2009), em que o contato com a natureza foi considerado uma importante variável para a utilização do parque. 
Particularmente, os sujeitos do presente estudo alegaram que os referidos espaços transmitem tranquilidade, paz e relaxamento.

Em relação à subcategoria Espaço de Lazer e Promoção da Saúde, foi identificado que um dos motivos para a utilização dos espaços delimitados é a busca pela saúde, conforme relatou o Entrevistado 15 da Jaqueira: "Primeiro lugar minha saúde. E como se diz aí, a corrida, os parques, faz parte do nosso plano de saúde que eu tenho 70 anos... pra mim é muito importante a prática de esporte, consequentemente, eu venho aqui pra Jaqueira". A partir desta fala, percebe-se que esses espaços estimulam as pessoas a praticarem atividades físicas. Neste sentido, para Bendimo-Rung, Mowen, Cohen, (2005), os parques são importantes para promoção da saúde, em que as características ambientais podem influenciar na realização de atividade física.

As respostas advindas dos atores sociais que utilizam o Parque da Jaqueira apontaram as variáveis socialização e a busca pelo bem estar, conforme destacou o Entrevistado 8: "primeiramente agora é saúde, e segundo, é bem estar mesmo. É você tirar o estresse do dia a dia". Em relação ao Calçadão, observou-se a preocupação dos indivíduos em manter a forma, como afirmou o Entrevistado 52 "gosto de praticar esporte. Eu gosto de me cuidar, então é o principal motivo". De fato, os relatos dos entrevistados deixam clara a preocupação com a saúde, confirmando que os espaços públicos de lazer são lugares que propiciam e incentivam a promoção da saúde, sendo importante ressaltar a necessidade do acompanhamento de um profissional capacitado que oriente os indivíduos nas suas práticas. Portanto, são necessárias estratégias para motivar os usuários a buscar hábitos e estilo de vida saudáveis. Neste contexto, os programas e campanhas relacionados à promoção de um estilo de vida ativo são destacados por caracterizarem uma estratégia para melhorar os hábitos saudáveis da população (MENDONÇA; TOSCANO; OLIVEIRA, 2009).

Observou-se que, em relação à subcategoria Atividade Física, a caminhada e a corrida foram mencionadas com maior frequência. No Parque da Jaqueira a musculação e a yoga também foram citadas 
pelo fato deste espaço oferecer aos seus frequentadores uma pequena estrutura de equipamentos de musculação e um projeto de yoga desenvolvido pela Prefeitura da Cidade do Recife. Por outro lado, no Calçadão foram mencionados o ciclismo, futebol e tênis, devido ao maior número de espaço para a prática do futebol e ciclismo, além de disponibilizar quadras de tênis.

Desse modo, esses espaços são construídos, propositalmente, como estratégia de incentivar a prática de atividade física entre os usuários dos espaços públicos de lazer. Tais atividades estão também presentes nos estudos de Mórmul e Biondi (2004), cujo motivo principal que leva a população aos parques da cidade é a prática de atividades físicas. Estes resultados também encontram respaldo no estudo de Mendonça, Toscano e Oliveira (2009), afirmando que para a promoção da atividade física são necessárias intervenções ambientais e políticas públicas elaboradas no sentido de influenciar os indivíduos a participarem de tais atividades.

Assim, na medida em que esses espaços são atrativos para os usuários, eles se tornam identitários, relacionais e históricos (AUGÉ, 1994), moldados a partir das interações humanas e não se limitando a uma mera ocupação dos espaços, fazendo com que os frequentadores criem uma aproximação e relação com os ambientes de lazer. Espaços estes, que os indivíduos se relacionam, vivem, trocam experiências e, assim, levam-nos a uma melhor qualidade de vida.

Esses achados enfatizam a importância dos espaços públicos de lazer, pelas diferentes possibilidades que estes oferecem aos seus usuários, podendo motivá-los por meio da interação social, experiências de lazer e busca por hábitos e estilo de vida saudáveis. Assim, são necessárias estratégias para elaboração de políticas públicas que conduzam a uma maior participação e utilização desses espaços, valorizando à qualidade de vida dos usuários, bem como valorizando e investindo nos espaços públicos de lazer. 


\section{CoNSIDERAÇõEs FINAS}

Os fatores motivacionais para se frequentar os espaços públicos de lazer estão relacionados à busca por hábitos saudáveis e interação social. O contato com a natureza, a proximidade das residências dos usuários, as características e a segurança desses espaços também são considerados fatores motivacionais. Em adição, especula-se que, o fato de um maior número de mulheres frequentando o Parque da Jaqueira, pode assinalar uma preocupação com a segurança.

Foi constatado que as atividades realizadas no interior dos espaços estudados estão relacionadas com as características estruturais que o espaço oferece. Nesse sentido, é preciso ater-se à qualidade desses espaços, para que isto não venha a ser um fator que afaste os indivíduos dos ambientes de lazer. É necessária a colaboração de profissionais da saúde, urbanistas, arquitetos, entre outros profissionais, para que, de forma conjunta, elaborem estratégias de intervenção a fim de que estes lugares continuem motivando seus usuários no sentido de frequentar os citados espaços regularmente.

Sugere-se a realização de novos estudos relacionados aos espaços públicos de lazer, objetivando ampliar essa discussão entre grupos que não frequentam esses ambientes, possibilitando identificar os motivos que fazem as pessoas não utilizarem os espaços públicos de lazer. 
Society, culture and health: motivation for the use of public space of leisure

Abstract: The aim of this research was the identification and analysis of motivational factors that influence social actors to use public places of leisure. It is a descriptive field research with qualitative approach, performed with 80 regulars of Parque da Jaqueira and Calçadão de Boa Viagem in Recife-PE. The data was analyzed using qualitative content analysis. The results indicate that the motivational factors to attend the public places of leisure are related to the pursuit of healthy habits and social interaction. Therefore, they provide quality of life, satisfaction and welfare to the regulars.

Keywords: Leisure activities. Health promotion. Motivation.

Sociedad, cultura y salud: la motivación en el uso del espacio público para el ocio

Resúmen: El propósito del estudio fue identificar y analizar los factores motivacionales que influyen los actores sociales para el uso de los espacios públicos de ocio. Se trata de un campo de carácter descriptivo con enfoque cualitativo, realizado con 80 personas en Parque da Jaqueira y Calçadão de Boa Viagem, Recife-PE. La evaluación de los datos fue a través de análisis de contenido. Los resultados indican los factores de motivación para asistir los espacios públicos de ocio relacionados con la consecución de hábitos saludables y la interacción social. Luego, pueden ofrecer a sus usuarios calidad de vida, satisfacción y bienestar.

Palabras clave: Actividades de ocio. Promoción de la Salud. Motivación

\section{REFERÊNCIAS}

AUGÉ, Marc. Não-Lugares: introdução a uma antropologia da supermodernidade. São Paulo: Papirus, 1994.

BAKER, Elisabeth et al. Do recreational resources contribute to physical activity? Journal of physical activity and health, Champaign, v. 5, n. 2, p. 252-261, mar. 2008. 
BANKS, Marcus. Dados visuais para pesquisa qualitativa. Porto Alegre: Artmed, 2009.

BARDIN, Laurence. Análise de conteúdo. Lisboa: Edições 70, 2009.

BEDIMO-RUNG, Ariane Lissan; MOWEN, Andrew; COHEN, Deborah. The significance of parks to physical activity and public health - A conceptual model. American Journal of Preventive Medicine, San Diego, v. 28, n. 2, p. 159-168, fev. 2005.

BRASIL. Conselho Nacional de Saúde. Resolução 196/96. Brasília, DF, 2003.

CASSOU, Ana Carina Naldino. Características ambientais de utilização e nível de atividade física dos usuários de parques e praças de Curitiba, PR. 2009. 153f. Dissertação (Mestrado). Curso de Educação Física, Departamento de Educação Física, UFPR, Curitiba, 2009.

COHEN, Debora et al. Contribution of parks to physical activity. American Journal of Public Health, Birmingham, v. 97, n. 3, p. 509-514, mar. 2007.

COLLET, Carine et al. Fatores determinantes para a realização de atividades físicas em parque urbano de Florianópolis. Revista Brasileira de Atividade Física \& Saúde, Pelotas, v. 13, n. 1, p. 15-23, jan./abr. 2008.

FERREIRA, Paulo Emílio Buarque. A apropriação do espaço urbano e as políticas de intervenção urbana e habitacional no centro de São Paulo. 2007. 131f. Dissertação (Mestrado). Departamento de Arquitetura e Urbanismo, USP, São Paulo, 2007.

FLORINDO, Alex Antonio et al. Percepção do ambiente e prática de atividade física em adultos residentes em região de baixo nível socioeconômico. Revista Saúde Pública, São Paulo, v. 45, n. 2, p. 302-310, abr. 2011.

FONTANELLA, Bruno José Barcellos; RICAS, Janete; TURATO, Egberto Ribeiro. Amostragem por saturação em pesquisas qualitativas em saúde: contribuições teóricas. Cadernos de Saúde Pública, Rio de Janeiro, v. 24, n. 1, p. 17-27, jan. 2008.

LEITE, Maria Angela Faggin Pereira. Um sistema de espaços livres para São Paulo. Estudos Avançados, São Paulo, v. 25, n. 75, p. 159-174, jan./abr. 2011.

MENDONÇA, Braulio Cesar de Alcantara; TOSCANO, José Jean de Oliveira; OLIVEIRA, Antônio Cesar Cabral. Do diagnóstico à ação: experiências em promoção da atividade física programa Academia da Cidade Aracajú: promovendo saúde por meio da atividade física. Revista Brasileira de Atividade Física \& Saúde, Pelotas, v. 14, n. 3, p. 211-216, set./dez. 2009.

MEUNIER, Isabelle Maria Jacqueline. Percepções e expectativas de moradores do grande Recife-PE em relação aos parques urbanos. Revista da Sociedade Brasileira de Arborização Urbana, Piracicaba, v. 4, n. 2, p. 35-43, jun. 2009. 
MÓRMUL, Maria Letícia Parizotto; BIONDI, Daniela. Parques urbanos de Curitiba/PR: Qual a preferência de seus usuários? In: VII Encontro Nacional de Ensino de Paisagismo, 2004, Belo Horizonte. Anais... Belo Horizonte: ENEPEA, 2004.

NARCISO, Carla Alexandra Filipe. Espaço público: acção política e práticas de apropriação. Conceito e procedências. Estudo e pesquisa em psicologia, Rio de Janeiro, ano 9, n. 2, p. 265-291, jul./dez. 2009.

OLIVEIRA; Marcelo Ponestki; RECHIA, Simone. O espaço cidade: uma opção de lazer em Curitiba (PR). Licere, Belo Horizonte, v. 12, n. 3, set. 2009.

OLIVEIRA, Marcelo Ponestki. Práticas corporais em meio a natureza: o caso do parque Barigui. 2009. 107f. Dissertação (Mestrado) - Mestrado em Educação Física, UFPR, Curitiba, 2009.

RECHIA, Simone. Parques públicos de Curitiba: a relação cidade-natureza nas experiências de lazer. 2003. 189f. Tese (Doutorado) - Curso de Educação Física, Faculdade de Educação Física, UNICAMP, Campinas, 2003.

RECHIA, Simone. Espaço e planejamento urbano na sociedade contemporânea: políticas públicas e a busca por uma marca identitária na cidade de Curitiba. Movimento, Porto Alegre, v. 11, n. 3, p. 49-66, set./dez. 2005.

RECHIA, Simone; BELTRÁN, Javier Oliveira. Parques urbanos de Barcelona: relação entre usos principais e combinados, a diversidade nas formas de apropriação e a segurança. Movimento, Porto Alegre, n. 16, v. 3, p. 181-202, jul./set. 2010.

REIS, Rodrigo Siqueira. Determinantes ambientais para a realização de atividades físicas nos parques urbanos de Curitiba: uma abordagem sócioecológica da percepção dos usuários. 2001. 163f. Dissertação (Mestrado) - Curso de Educação Física, Centro de Desporto da Universidade Federal de Santa Catarina, UFSC, Florianópolis, 2001.

ROTTA, Ana Maria Solleti; PIRES, Giovani de Lorenzi. "Se essa praça, se essa praça fosse nossa...": espaços públicos e possibilidades para o lazer dos jovens de Caçador/SC. Licere, Belo Horizonte, v. 13, n. 2, p. 1-22, jun. 2010.

RYAN, R.M.; DECI, E.L. Self-determination theory and the facilitation of intrinsic motivation, social development, and well-being. American Psychologist, Washington, v. 55, p. 68-78, jan. 2000.

SANTOS, Edmilson Santos. Perfil dos usuários do Parque Esportivo Eduardo Gomes/ Canoas/RS. Arquivos em Movimento, Rio de Janeiro, v. 3, n. 1, p. 70-86, jan./ jun. 2007.

SCHWARTZ, Gisele Maria. A Aventura no âmbito do lazer: as AFAN em foco. In: . Aventuras na natureza: consolidando significados. Jundiaí: Fontoura Editora, 2006. p. 23-33. 
SILVA, Diego Augusto Santos; PETROSKI, Edio Luiz; REIS, Rodrigo Siqueira. Barreiras e facilitadores de atividades físicas em frequentadores de parques públicos. Motriz, Rio Claro, v. 15, n. 2, p. 219-227, abr./jun. 2009.

SILVA, E. A. P. C. O lugar de lazer na cidade: um espaço de diálogo e de vivências. 2011. 87f. Dissertação (Mestrado) - Curso de Educação Física, Universidade de Pernambuco/ Universidade Federal da Paraíba, UPE/ UFPB, Recife, 2011.

STIGGER, Marco Paulo; MELATI, Fernanda; MAZO, Janice Zarpellon. Parque Farroupilha: memórias da constituição de um espaço de lazer em Porto Alegre, Rio Grande do Sul- Brasil. Revista da Educação Física/UEM, Maringá, v. 21, n. 1, p. 127-138, 1.trim, 2010.

WORLD HEALTH ORGANIZATION. Health promotion evaluation: recommendations to policymakers. Copenhagen: European Working Group on Health Promotion Evaluation, 1998.

ZIPEROVICH, Pablo Carlos. Espaço urbano de esporte, lazer e recreação: relação público-privado, gestão e controle social. In: SILVA, Katharine Ninive Pinto; SILVA, Jamerson Antônio de Almeida. (Orgs.). Recreação, esporte e lazer- Espaço, tempo e atitude. Recife: Instituto Tempo Livre, 2007. p. 165-187.

Recebido em: 21.08.2011

Aprovado em: 27.03.2012 
